Military Technical College

Kobry El-Kobbah, Cairo, Egypt

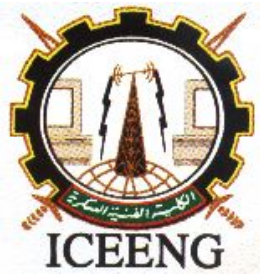

ICEENG

\section{$10^{\text {th }}$ International Conference on Electrical Engineering}

\author{
ICEENG 2016
}

\title{
DESIGN, CONSTRUCTION AND STUDY OF SMALL SCALE VERTICAL AXIS WIND TURBINE BASED ON MAGNETICALLY LEVITATED AXIAL FLUX PERMANENT MAGNET GENERATOR
}

\section{Ghulam Ahmad ${ }^{1}$}

Electrical Engineering \& Technology, University of Gujrat, Gujrat, Pakistan. g.ahmad4@hotmail.com ${ }^{1}$

\begin{abstract}
A small scale vertical axis wind turbine (VAWT) with axial flux permanent magnet (AFPM) generator has been designed and magnetic levitation method is used to increase the efficiency of this type of wind turbine [1]. Magnetic levitation is inserted by using rare earth permanent magnets, the repelling force of magnets are used to suspend the rotating part of both turbine and generator. Moreover, design of simple generator which can easily drive without geared mechanism, lessen cost and the complexity of the system by reducing the quantity of driving components. Three phase output is obtained from designed generator which is converted into direct current through three-phase rectifier to charge the batteries. The performance of proposed prototype is also tested experimentally. The turbine performs as predicted by the design process.
\end{abstract}

Index Terms - Wind energy, Magnetic Levitation, Vertical axis wind turbine, Permanent magnet axial flux generator.

\section{Introduction}

Rapid depletion of fossil fuels, increasing energy costs and environmental issue have been focused due to excessive fossil fuel consumption therefor the renewable resources are becoming a more viable technology for electrical power generation. Among renewable resources, wind turbines are capable of producing higher power in a smaller place when the wind is blowing at a constant rate $[2,3]$. Although horizontal axis wind turbine (HAWT) are used commercial for high capacity, the interest have been growing, to inserting new technologies in small and medium size VAWT. Small scale VAWT are needed more development for efficiently use on domestic level.

\author{
Suhail Aftab ${ }^{2}$ \\ Electrical Engineering \\ University of Engineering \& Technology, Pakistan \\ saqureshi@uet.edu.pk ${ }^{2}$
}

\begin{abstract}
Use of gear mechanism is the major drawback of wind turbines. This mechanism is inefficient and increases the cost of the wind turbine. This mechanism can be replaced by using direct drive generator system which reduce power loss, maintenance and cost. This model overcomes the issues of conventional AFPM by dual rotor plate configuration [4]. Moreover bearing also can be replaced with magnetic levitation, which provides frictionless motion.
\end{abstract}

\section{Turbine Design}

In VAWT the shaft is rotated around vertical axis. To produce power rotation of these turbines are perpendicular to the direction of wind. In VAWT, s generator is also connected in perpendicular near bottom of the turbine [5].

\section{A. Power available in wind}

The available energy in the wind is actually the energy contained in moving air particles such as oxygen, nitrogen, hydrogen, etc [6]. This energy is more commonly known as kinetic energy. Kinetic energy in a moving system can be calculated using the following formula

$$
E=\frac{1}{2} m v^{2}
$$

Where, $\mathrm{E}$ is kinetic energy $(\mathrm{J}), \mathrm{M}$ is system mass $(\mathrm{Kg})$ and $\mathrm{V}$ is the velocity of the moving system $\left(\mathrm{m} / \mathrm{s}^{2}\right)$. Power is measure of energy produced or used over a period of time. The distance achieved by the air particles is the product of their velocity and the time they take to reach that particular distance. The equation 1 can be further developed 
to get an expression of power for the wind turbine calculation

$$
P=\frac{1}{2} \rho A v^{3}
$$

Where, $p$ is the mass density of air above the sea surface $\left(\mathrm{Kg} / \mathrm{m}^{3}\right)$ which is $1.225 \mathrm{~kg} / \mathrm{m}^{3}$, A is the cross-sectional area $\left(\mathrm{m}^{2}\right)$ and $\mathrm{V}$ is the velocity of the moving system $\left(\mathrm{m} / \mathrm{s}^{2}\right)$. The magnitude of the power depends heavily on the speed of the wind. Small wind turbine needs strong wind in order to produce an extensive amount of power $[7,8]$.

\section{B. Determine the size of turbine}

The length of rotor blades and the radius of rotor directly proportional to the output power of the turbine. Size of the wind turbine is also known as the swept area of that particular turbine [9]. Figure 1 shows the dimension of a wind turbine. Swept area of turbine differs according to the shape of rotor configuration. Because in HAWT shaft rotates around horizontal axis so the swept area is calculated by different formula with respect to VAWT. The swept area of this turbine is calculated by using following formula [10].

$$
A=2 R H
$$

Where, A is the turbine Area $\left(\mathrm{m}^{2}\right), \mathrm{R}$ is the radius of turbine $(\mathrm{m})$ and $\mathrm{H}$ is the height of the blade (m).

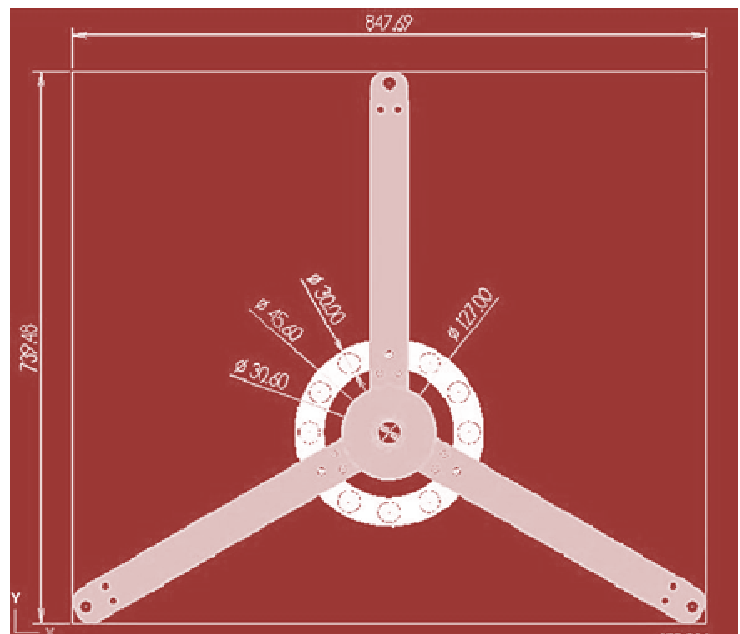

Fig 1: Dimension of Wind Turbine

Because the area of turbine connect the air to obtain its energy and convert into rotational energy, So as the area is greater it contact more air and can be obtain more power from the wind at same wind speed [11,12].

\section{Airfoil of the turbine}

Darrieus type turbine blades use lift forces from wind to rotate the blades. The blades have an airfoil shape. Turbine blade design has been selected keeping in mind the availability of data of the particular airfoil. The shape of blade and the thickness is determined by the data of such specific airfoil. There is enough data is available to review the aerodynamic characteristics in documents issued by National Advisor Committee for Aeronautics [7] and Sandia National Laboratory [8]. Figure 2 shows the NACA airfoil design. In these documents for several NACA airfoils, lift and drag coefficient with Reynolds number and 0 to $180^{\circ}$ ranging angle of attack are provided.

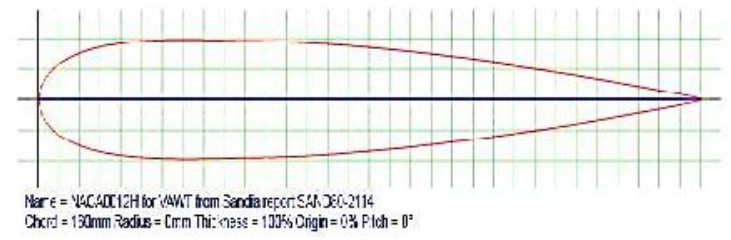

Fig 2: NACA Air Foil

\section{Determine the blade quantity}

Smoothness of rotor operation is directly affected by increasing and decreasing the quantity of blades of VAWT. After determining the blades quantity very important factor solidity has contemplated. Solidity is ratio between total area of blade and the radius of turbine. Figure 3 shows the blade area and dimension. Total area of blade includes number of blade and the chord length of the blade. Selfstarting of the turbine can be effected by this non dimensional parameter [15]. Solidity straight blade VAWT can be calculating by using following formula

$$
\sigma=\frac{N c}{R}
$$

Where, $\mathrm{N}$ is the quantity of the blade, $\mathrm{C}$ is the length of chord (m) and $\mathrm{R}$ is the radius of rotor $(\mathrm{m})$. Power coefficient is also depending on the blades quantity which decreases as the number of blade decreases significantly $[16,17]$.

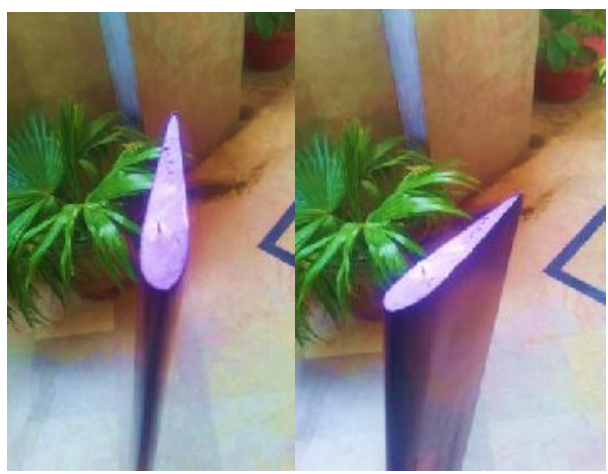

Fig 3: Blade Area and Radius

\section{E. Efficiency of the wind turbine}

In energy conservation process such as mechanical energy into electrical energy most of the power available in the wind is lost. The ratio between the power generated by a wind turbine and the power 
available in the wind is called the overall efficiency of wind turbine [18].

$\eta_{\text {total }}=\frac{P_{\text {output }}}{P_{\text {input }}}$

There are two types of efficiency in a wind turbine the first one is the rotor efficiency $\left(C_{p}\right)$ and the second on is the generator efficiency $(\eta)$. The rotor efficiency of a wind turbine depends on the mechanical design of the rotor blades. Power coefficient is used to calculate the amount of power captured by turbine that was available in the wind

$$
C_{p}=\frac{\text { captured mechanical power by blade }}{\text { Available power in wind }}
$$

On the other hands, the generator efficiency depends mostly on the electrical design of the generator [19].

$$
P_{\text {output }}=\frac{1}{2} \rho A v^{3} C_{p} \eta
$$

To get the rotor efficiency the mechanical power of the rotor has to be calculated. One can start by measuring the rotational speed ( $\omega)$ as well as the mechanical torque $(T)$ of the rotor. So, mechanical power can be calculated using following formula

$P_{\text {mechanical }}=T \omega$

Where, $\mathrm{T}$ is the mechanical torque of the rotor $(\mathrm{Nm})$ and $\omega$ is the rotational speed of the rotor $(\mathrm{rad} / \mathrm{s})$. This mechanical power is then compare with the power in the wind to get rotor efficiency. To get the generator efficiency one can measure the induced voltage at the terminal of the generator and induced current flowing in the circuit. So, the electrical power can be calculated by using following formula

$P_{\text {slectrical }}=V I$

Where, $\mathrm{V}$ is the induced voltage $(\mathrm{V})$ and $\mathrm{I}$ is the induced current (A). This electrical power can be compared with the mechanical power to get generator efficiency [31]. Assuming there is no loss in the conversion process the following equation is applicable [20, 21].

$$
\begin{aligned}
P_{\text {mechanical }} & =P_{\text {electrical }} \\
T \omega & =V I
\end{aligned}
$$

\section{Magnetic Levitation}

The idea of magnetic levitation is to make complete levitating rotor by using only permanent magnets to nullify the weight of rotor and to avoid any mechanical contact between the rotor and surrounding mechanical parts. Levitation is done by using two sets of axially magnetized ring magnets which are placed in such a way so that they are in repelling state. The first magnet is put on shaft and the second magnet is put under the supporting hub. Due to the repulsion of magnets, the hub and other rotating parts are levitated and its weight is partially nullified [22]. It is partially nullified because the center of gravity is not exactly located at the center of the rotor blades. When the rotor is forces to rotate the center shaft will continuously hit any adjacent mechanical part surrounding it. To get the magnitude of the repelling force between two identical magnets online calculator from $\mathrm{K} \& \mathrm{~J}$ Magnetics, Inc. is used. By using the repelling magnetic force calculator it is known that the permanent magnets used for the vertical levitation in our project are able to produce repelling force of $78.4 \mathrm{~N}$ at $1 \mathrm{~cm}$ distance from the surface of the magnets with maximum repelling force of about 124.4 $\mathrm{N}$ as shown in figure 4 . These magnets can be used to lift the rotor of wind turbine [23, 24]. Final dimension of magnets for vertical dimension are:

Outer diameter $=45 \mathrm{~mm}$

Inner diameter $=35 \mathrm{~mm}$

Thickness $=5 \mathrm{~mm}$

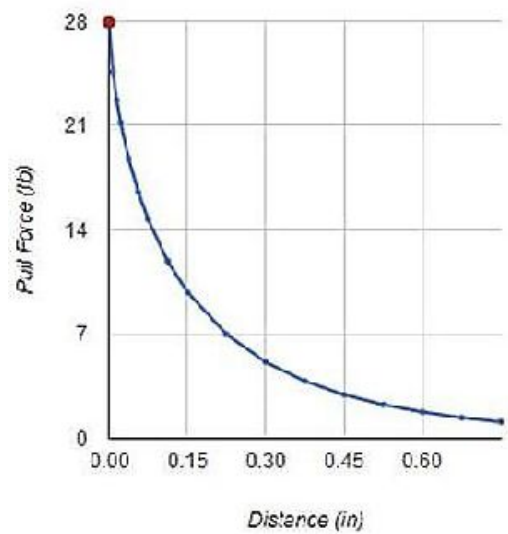

Fig 4: Selected Magnet Results

\section{Generator Design}

The generator system can be classified into the permanent magnet (PM) machine and the electrically excited (EE) machine. A number of permanent magnets generator topologies can be used for small scale wind turbine such as, axial flux generator, Toroidal flux generator, and Radial flux generator [25]. Term axial flux comes from the fact that in this particular type of generator, the permanent magnets placed on the rotor plates have axial magnetization.

Generated electricity basically follows Faraday's Law of induction. This law state that the induced electromotive force (EMF) in any closed circuit is equal to the time rate of the magnetic flux through the circuit. The polarity of the induced emf depends on a certain rule, as stated by Lenz's Law.

$e=N \frac{d \emptyset}{d t}$ 


\section{A. Rotor Plates}

To establish the closed magnetic circuit rotor plates are made of ferromagnetic material. One possible material and widely available is the market is iron. For strong magnetic field two rotor plates are used. Axially magnetized disc magnets are used in the rotor plates. Magnets are arranged in N-S-N-S arrangement circumferentially around the rotor [26]. The magnets on each rotor disc are aligned with $\mathrm{N}$ facing $\mathrm{S}$. Rotor plate dimensions shown in figure 5. For making three phases out waveform there is certain ratio to be followed between the number of stator coils and the number of permanent magnets on the rotor plates. The prototype of rotor plate made of iron shown in figure $6[27,28]$.

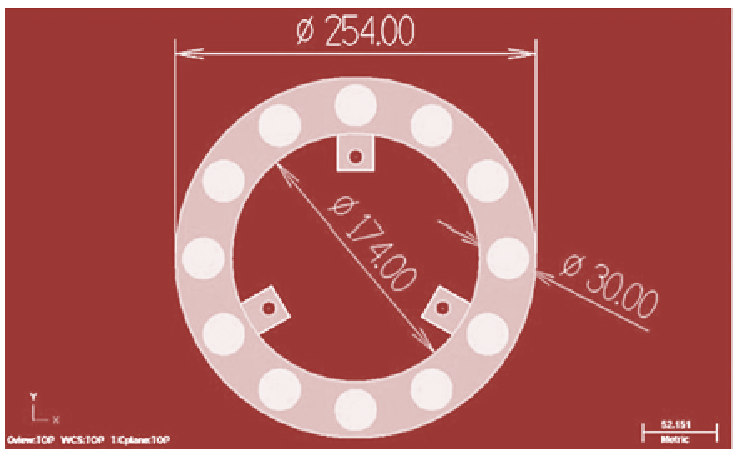

Fig 5: Dimension of Rotor Plate

The ratios respectively are $3: 4,6: 8,9: 12,12: 16$, and so on. Ratio of 9:12 is chosen considering the availability of space on the rotor plates. By this configuration only one coil can be fully energized by the magnets at a time which also means there is only on peak voltage at a time.

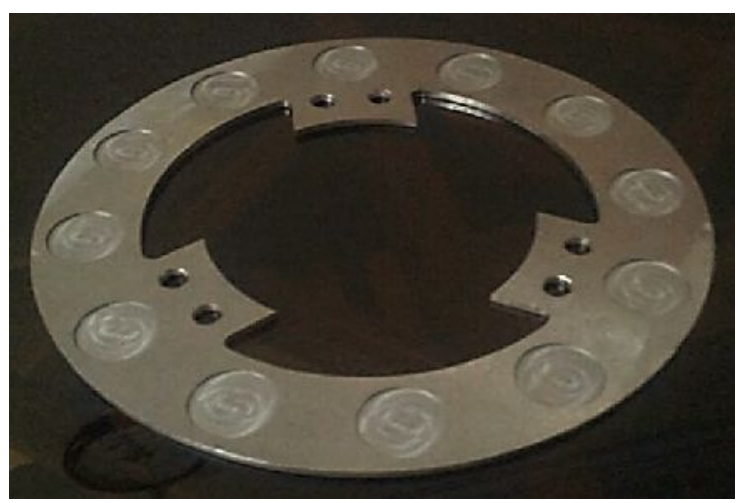

Fig 6: Prototype of Rotor Plate made of Iron

\section{B. Stator Plates}

Coils are needed to produce certain voltage. To hold the magnet wire coil stator plate is made of non-conducting, non-magnetic material. Because small scale wind turbine is design to a charge $12 \mathrm{~V}$ battery. So at particular wind speed, generator must be able to produce $12 \mathrm{~V}$. To determine the number of coil turns, Faraday's Law of induction can be applied.

$N=\frac{e}{\frac{d \emptyset}{d t}}$

According to this formula first magnetic field density is calculated to find the number of turns. The value of the magnetic field density at each extreme point on the coil can be calculated using online magnetic field density calculator by $\mathrm{K} \& \mathrm{~J}$ Magnetics, Inc as shown in figure 7 and flux density of rotor magnet shown in figure 8 [24].

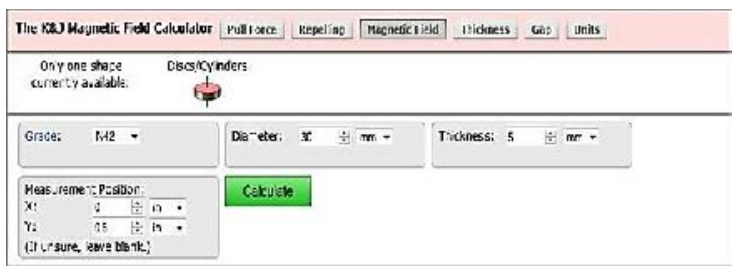

Fig 7: K \& J Magnetic Field Calculator

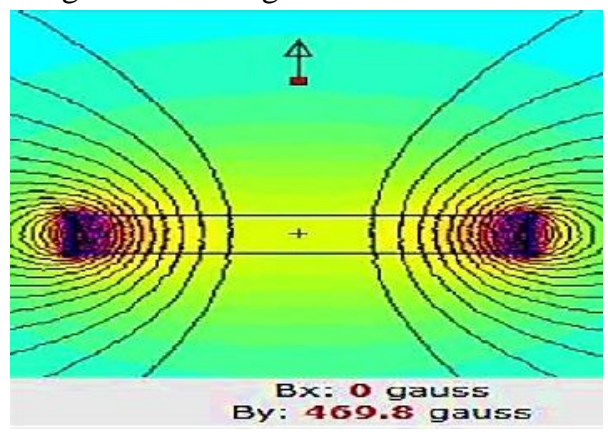

Fig 8: Flux Density of Rotor Magnet

Another parameter that is essential to determine the number of turn that is the changing of area with respect to time. For this purpose first the coil is assumed to have circular cross-sectional area and diameter is equal to the diameter of permanent magnet. Figure 9 and 10 shows the stator plate and coil dimension and coil arrangement respectively. Now we have two circles one of the magnet and other of the coil $[12,29]$. Total area occupied by these two circles can be calculated using basic geometry, the mathematical equation is written below:

Total area occupied both circles $=($ area of the pie area of the rectangle) $\times 2$

Using above equation the area occupied by both circles is $0.00018 \mathrm{~m}^{2}$. 


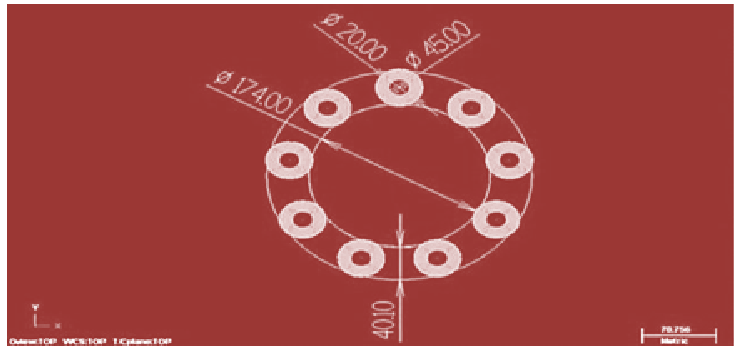

Fig 9: Stator Plate and Coil Dimension

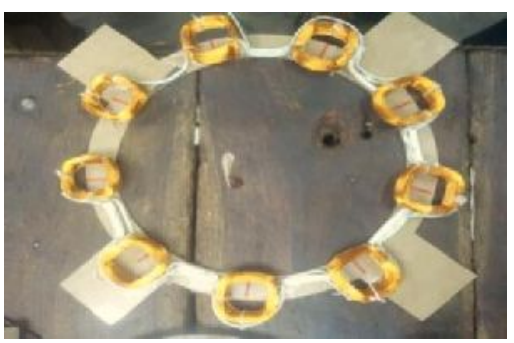

Fig 10: Coil Arrangement

\section{Three Phase Rectifier}

To make full wave three phase rectifier circuit six diodes are used. Using six diodes may have some problems but smooth output can be obtained from three phase input. In six diode configuration each diode operates for very short period of time. Many other power electronic components can be used for the rectification purpose [30].

\section{Results and Discussion}

A. Increase in Efficiency of the Rotor Plates due to magnetic levitation

Rotor blade's speed measurements have been conducted to check the performance of the magnetic levitation. These measurements were done at three different wind speeds provided by the fan. Increase in efficiency of the rotor shown in figure 12 .

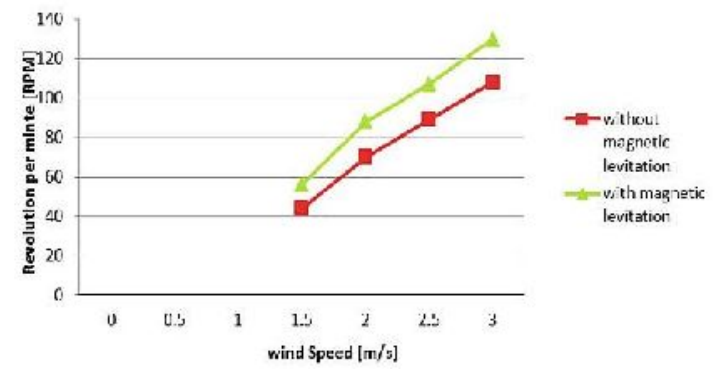

Fig 12: Total increase in efficiency of the rotor

The efficiency of the rotor blades at each particular wind speed can then be calculated. By averaging, the efficiency of the rotor blades increases by 23.6 $\%$. With increase of efficiency of about $23.6 \%$, the simple magnetic levitation using permanent is definitely worth the expense [31]. Complete magnetic levitation is required to hold the wobbling movement of the central shaft which is stable at lower wind speed. Figure 13 shows the prototype of magnetic levitation.

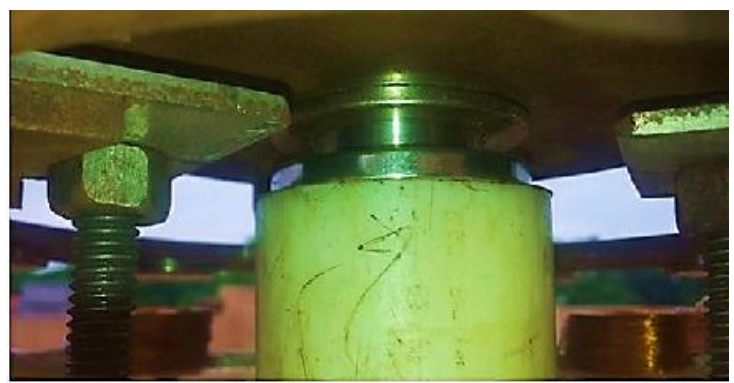

Fig 13: Magnetic Levitation in Prototype

\section{B. Stator Coil Performance}

The performance of the coil is tested at a number of different rotor's speed. The value of at the beginning was found by calculating the magnitude of it only at the center of the air gap. Air gap between rotor plates is shown in figure 14 .

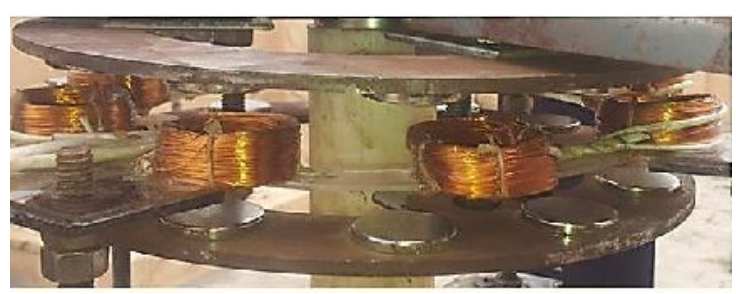

Fig 14: Rotor Stator Air Gap

Figure 15 compares the induced voltage and actual induce voltage in stator coil w.r.t to rotor speed.

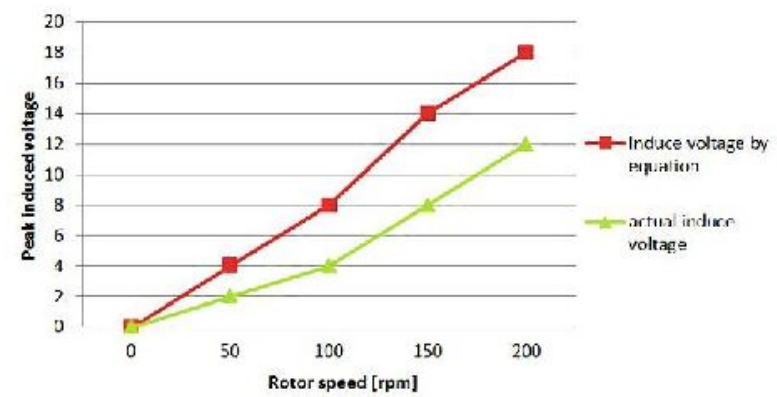

Fig 15: Performance of Stator Coil

Since results found are not quit similar because of wobbling movement of the rotor plates due to this movement the rotor stator air gap is increases which reduce the output. The stator plate is located between the two rotor plates. It is important to notice that in reality, the air gap is not uniform throughout the rotor-stator construction. Actual induced voltage is shown in figure 16 . 


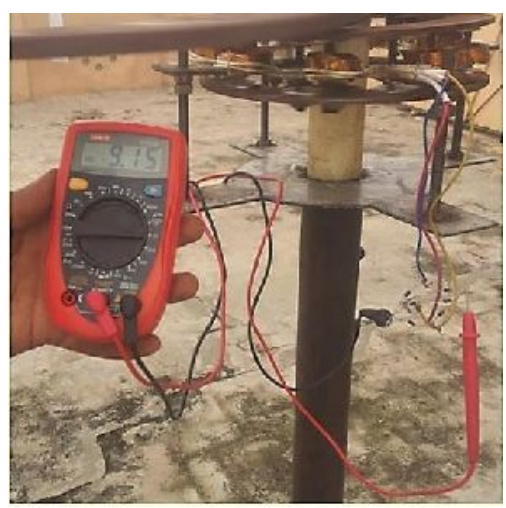

Fig 16: Actual Induced Voltage

\section{Output Power of the Wind Turbine}

The output power of the wind turbine is measured at wind speed of about $2 \mathrm{~m} / \mathrm{s}$, with a number of different resistances connected to the output of the bridge rectifier. Power, voltage and current transfer on different resistance value shown in figure 17 and actual readings at wind speed $2 \mathrm{~m} / \mathrm{s}$ shown in figure 18 [32,33].

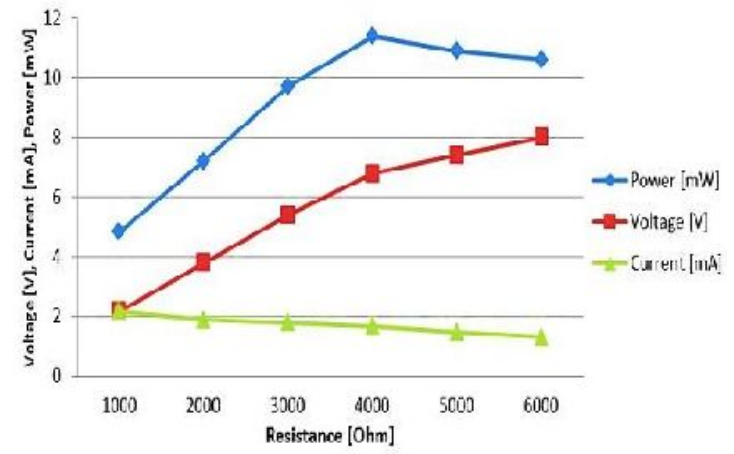

Fig 17: Power Transfer at wind speed of about 2 $\mathrm{m} / \mathrm{s}$.

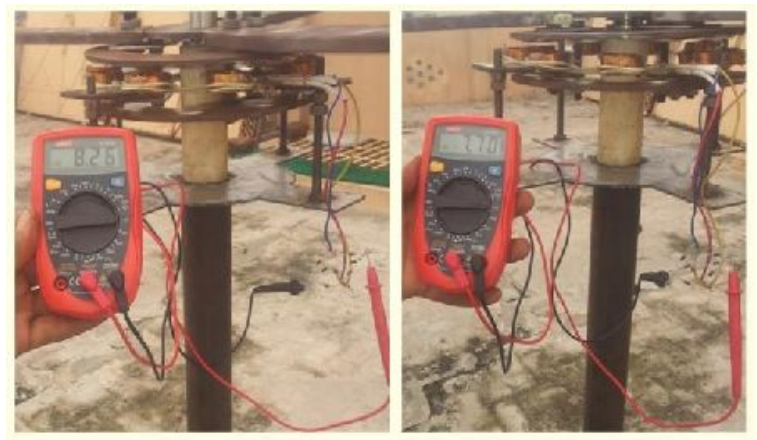

Fig 18: Readings at Wind Speed of about $2 \mathrm{~m} / \mathrm{s}$.

Complete prototype of wind turbine design is shown in figure 20.

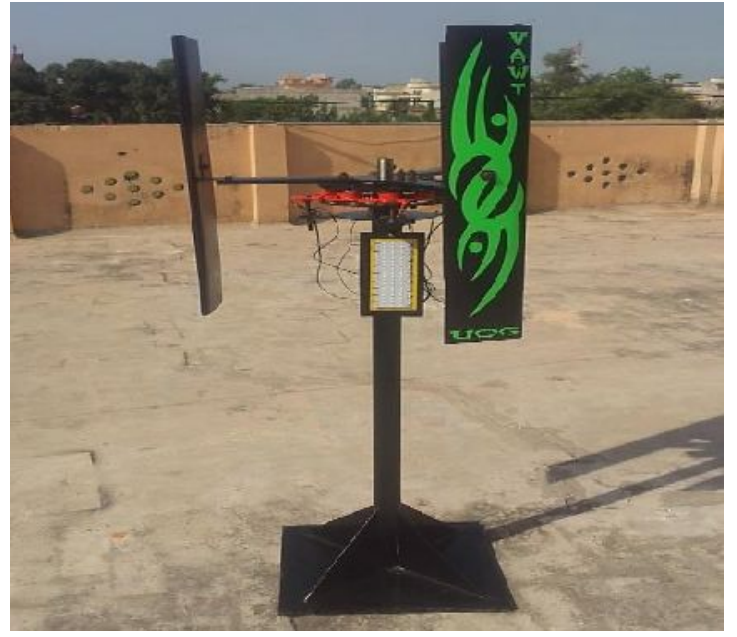

Fig 20: Wind Turbine Prototype

D. Rectified Three Phase Output of the Generator The voltage signal of the rectified three-phase voltage of the star configuration can be seen in figure 19 . The voltage ripples become much more visible and higher in magnitude at higher frequency.

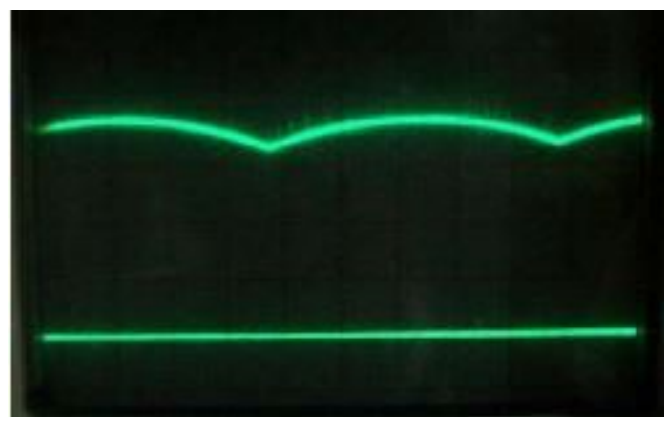

Fig 19: Rectified Three Phase Output

\section{Conclusion}

In conclusion, a vertical axis wind turbine is successfully built. Magnetic levitation is effectively added in our designed prototype which reduces the friction by suspending the rotating parts of both turbine and generator. Magnetic levitation is inserted by using rare earth permanent magnets. The efficiency of the wind turbine is increased $23.6 \%$ due to the magnetic levitation. Simple direct drive axial flux permanent magnet generator is also successfully built which provide three phase Ac output. We easily convert this output into DC supply by using three phase rectifier. There is no driving component instead of two rotor plates, therefore the cost is reduced. The stator of our designed generator is made to provide the voltage level for charging the batteries. The electrical design of the stator coils is made based on Faraday's law of induction.

\section{Recommendation}


The designed project functioned properly after testing but there are many things that can be improved upon. In making of wind turbine there are some flaws of unbalancing and self-starting. These flaws are due to the lack of resources for making the blades and other complicated parts. The output power of the wind turbine is greatly affected by the wind speed. The only mechanical parameter of the wind turbine that can be designed so that higher output power can be obtained is the cross-sectional area of the rotor blades. If higher output power is desirable at lower wind speed, the size of the rotor blades must be increased. It is important to remember that with higher output power, the diameter of the enameled copper wire must also be increased.

\section{References}

[1] Ahmed, Ashraf, L.Ran and Jim R.Bomby, "New Constant Electrical Power Soft-Stalling Control for Small Scale VAWTs", IEEE Transactions on Energy Conversion, 2010.

[2] M. Benedict, L. Vinod, J. Pino and C. Inderjit, "Fundamental understanding of the physics of a small-scale vertical axis wind turbine with dynamic blade pitching: an experimental and computational approach", 54th AIAA/ ASME/ASCE/AHS/ASC Structures, Structural Dynamics, and Materials Conference, Boston, Massachusetts, pp.98-107, 8-11, April, 2013.

[3] Najib, A.M, M.A Mustafa, "Regenerative Energy Air Flow System for Cooling Tower", Applied Mechanics and Materials, 2014.

[4] Changduk Kong, et al., "Structural Design of Medium Scale Composite Wind Turbine Blade", 13th International Conference on Composite Materials (ICCM-13), Beijing, China, pp.561, 3-8, July, 2001.

[5] "Lift (force)" https://en.wikipedia.org/wiki/Lift_(force)

Dated: 18 Aug 2015.

[6] Jacob Fraden, "Handbook of Modern Sensors, Physics, Design and Applications", 2016, ISBN: 978-3-319-19302-1 (Print) 978-3-319-19303-8 (Online).

[7] Aravind C.V, Rajparthiban, Rajparasad, Wong Y.V, "A novel magnetic levitation assisted vertical axis wind turbine Design procedure and analysis", 2012, IEEE $8^{\text {th }}$ International Colloquium on Signal Processing and its Applications, 2012. [8] Nikola Milivojevic, "Power and Energy Analysis of Commercial Small Wind Turbine Systems", 2010 IEEE International Conference on Industrial Technology. March, 2010.

[9] Van de Vyver, Jan, Tine L.Vandoorn, "Shaft Speed Ripples in Wind Turbines Caused by Tower Shadow and Wind Shear", IET Renewable Power Generation, 2014.

[10] Goh, H.H, S.W.Lee and K.T.K.Teo, "Renewable Energy Project: Project Management, Challenge and Risk", Renewable and Sustainable Energy Reviews, 2014.

[11] Aravind C.V, Rajparthiban, Rajparasad, Wong Y.V, "Mathematical Toolbox and Its Applications in the Development of Laboratory Scale Vertical Axis Wind Turbine", 2012 IEEE International Conference on Power and Energy (PECon) 2012. [12] Changduk, L. Haseung and M. Kim, "Aerodynamic and structural design of a high efficiency small scale composite vertival axis wind turbine blade", 18th international conference on composite materials, ICCM-18, Jeju Island, Korea, 21-26, August, 2011.

[13] "National Advisor Committee for Aeronautics" http://history.nasa.gov/naca/. Dated: 29 August 2015

[14] "Sandia National Laboratory" http://www.sandia.gov/ Dated: 29 August 2015

[15] Hara, Yutaka, Takahiro, Takanori, Takojo, "Effects of Blade Section on Performance of Butterfly Wind Turbines as Double Blade VAWTs", Journal of Fluid Science and Technology, 2015.
[17] A. Makarieva, et al., "Where do winds come from? A new theory on how water vapor condensation influences atmospheric pressure and dynamics", Atmospheric Chemistry and Physics, vol.13, no.2, pp.1039, 2013.

[18] Rodrigo J.A.Vieira and Miguel A.Sanz.Bobi, "Use Operation and Maintenance of Renewable Energy Systems", 2014, ISBN: 978-3-319-03223-8 (Print) 978-3-319-03224-5 (Online)

[19] Alkuhayli, Abdulaziz, Srinath and Badrul H.Chowdhury, "Reliability Evaluation of Distribution Systems Containing Renewable Distributed Generations", 2012 North American Power Symposium (NAPS) 2012.

[20] Aravind CV, RajparthibanR, Rajprasad and WongYN, "A novel magnetic levitation assisted vertical axis wind turbine-design procedure and analysis", 8th IEEE International colloquium on signal processing and its applications, Malacca, Malaysia, 23-25, March, 2012.

[21] P. Wannakarn, T. Tanmaneeprasert and IEEE Member,

"Design and construction of axial flux permanent magnet generated for wind turbine generated DC voltage at rated power 1500 w", 4th IEEE International conference on electrical utility deregulation, restructuring and power technology, Weihai, China, 6-9, July, 2011.

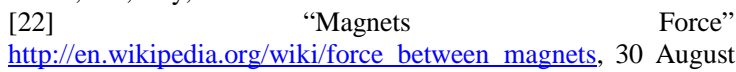
2015

[23] "Super Magnet Man" http://www.supermagnetman.net, 30 August 2015
[24]
"K\&J
magnetic
Calculator"

https://www.kjmagnetics.com/calculator.asp, 30 August 2015

[25] G. Price, D. Batzel, M. Comanescu and B. Muller, "Design and Testing of a Permanent Magnet Axial Flux Wind Power Generator", Proceeding of the 2008 IAJC-IJME International Conference, Tennessee, USA, 17-19, November, 2008.

[26] Gaing, Zwe Lee, Guan Jie Wnag and Jui An Chiang, "Implementation of a Coreless Axial Flux PM Generator for Vertical Axial Wind Turbine", Advanced Materials Research, 2013.

[27] "Derivative calculator" https://www.symbolab.com/solver/, 30 August 2015

[28] P. Wannakarn, T. Tanmaneeprasert and IEEE Member,

"Design and construction of axial flux permanent magnet generated for wind turbine generated DC voltage at rated power 1500w", 4th IEEE International conference on electrical utility deregulation, restructuring and power technology, Weihai, China, 6-9, July, 2011.

[29] A. Makarieva, et al., "Where do winds come from? A new theory on how water vapor condensation influences atmospheric pressure and dynamics", Atmospheric Chemistry and Physics, vol.13, no.2, pp.1039, 2013.

[30] "Generator connection" http://www.edaboard.com/ Thread 55707.html Dated: 28 August 2015. [23] "Rectifier", http://www.reuk.co.uk/Three -Phase-Bridge-Rectifier/.htm. Dated: 28 August, 2015.

[31] Howell R.., "Wind Tunnel and Numerical Study of a Small Vertical Axis Wind Turbine", Renewable Energy, 201002.

[32] Zhang, Li-xun, Ying-bin, Xiao Hong and Jian Guo, "Effect of Blade Pitch Angle on Aerodynamic Performance of Straight Bladed Vertical Axis Wind Turbine", Journal of Central South University, 2014.

[33] Chen j., J.Chen and C.Gong, "New Overall Power Control Strategy for Variable Speed Fixed Pitch Wind Turbines within the whole Wind Velocity Range", IEEE Transactions on Industrial Electronics, 2012. 